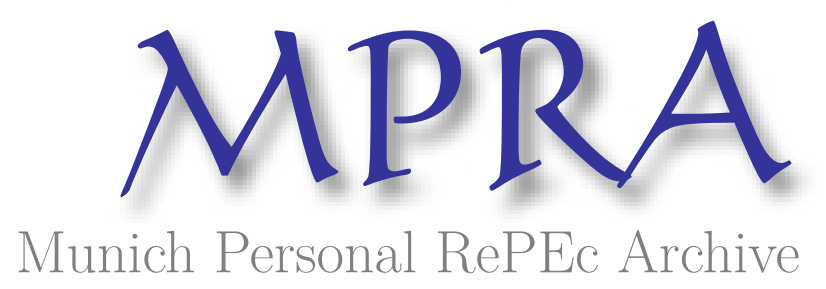

\title{
Better Health and Ambient Assisted Living (AAL) from a global, regional and local economic perspective
}

Eberhard, Birgid and Fachinger, Uwe and Henke, Klaus-Dirk Wirtschaftswissenschaftliche Dokumentation, TU Berlin

July 2009

Online at https://mpra.ub.uni-muenchen.de/16210/

MPRA Paper No. 16210, posted 14 Jun 2010 09:41 UTC 


\section{Birgid Eberhardt, Uwe Fachinger, Klaus-Dirk Henke Better Health and Ambient Assisted Living (AAL) from a global, regional and local economic perspective}

Birgid Eberhardt, Consultant Ambient Assisted Living, Association for Electrical, Electronic \& Information Technologies VDE e. V.

Univ.-Prof. Dr. Uwe Fachinger, Head of the Department Economics and Demography, Institute for Gerontology and Centre for Research on Ageing and Society, University of Vechta Univ.-Prof. Dr. Klaus-Dirk Henke, Chair of Public Finance and Health Economics, Institute for Economics and Commercial Law, Faculty Economics and Management, Technische Universität Berlin

Address

University of Vechta

Economics and Demography

Centre for Research on Ageing and Society

Driverstr. 22

D-49377 Vechta

uwe.fachinger@uni-vechta.de 


\section{ZUSAMMENFASSUNG}

Assistierende Technologien sollen der besseren Unterstützung bei der Deckung von Bedürfnissen des täglichen Lebens und zur Erhaltung von Selbständigkeit und Lebensqualität dienen. Es ist davon auszugehen, dass durch die kontinuierliche Entwicklung in der Medizin, der Medizintechnik sowie assistierender Technologien in der medizinischen und pflegerischen Versorgung neue Versorgungsmöglichkeiten geschaffen werden. Insbesondere im Zusammenhang mit der Entwicklung, der Förderung und der Ausgestaltung sogenannter altersgerechter Lebenswelten bzw. eines ambient assisted living ( $A A L)$ wird den unterstützenden Technologien und Informations- und Kommunkationstechniken von wissenschaftlicher und politischer Seite eine hohe gesellschaftliche und wirtschaftliche Relevanz zugewiesen.

Im Fokus stehen dabei vor allem die zukünftigen Älteren und ihre spezifischen Bedarfe und Ressourcen, die diese Technologien ihren individuellen Bedürfnissen entsprechend nutzen können sollen. Derartige Technologien können aber auch für Personen aus dem sozialen Umfeld der Älteren von hoher Relevanz sein. So können diese die Gestaltung des Zusammenlebens erheblich ändern - beispielsweise durch die Unterstützung bei der pflegerischen Versorgung durch Angehörige - und beispielsweise den Anbietern im Bereich der gesundheitlichen und pflegerischen ambulanten und stationären Versorgung neue Möglichkeiten der Versorgung bieten.

\section{ABSTRACT}

Assisting technologies aim to provide more support in the meeting of one's daily needs and the preservation of one's autonomy and quality of life. Continual developments in medicine, medical equipment, nursing and medical care are assumed to lead to new types of care being created. A high degree of social and economic relevance has been attributed to assisting technologies, as well as information and communication systems, by scientists and politicians alike, particularly in connection with the development, promotion and organization of so-called senior-friendly environments and with ambient assisted living (AAL).

Here the focus is especially upon the aged of the future, their specific demands and resources, which these technologies should be able to serve while adhering to their individual requirements. These new technologies can also be extremely relevant to people surrounding the elderly. They can make a considerable difference to the way in which people are able to live together for example by assisting the nursing care provided by close relatives and they may represent new opportunities to the providers of outpatient and impatient nursing and medical care. 


\section{CONTENTS}

1 Introduction

2 The economic impact of assisting technologies on nursing and medical care .................... 4

3 Better health and its contribution to productivity and economic growth .......................... 5

4 Status quo of AAL and possible growth markets with AAL ............................................... 8

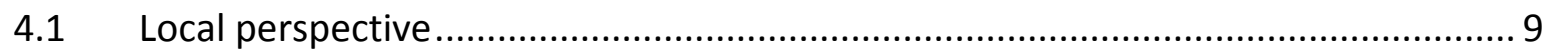

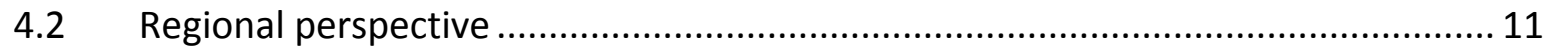

4.2.1 ICT technologies in combination with new services may help to overcome decreasing infrastructure ....................................................................... 15

4.2.1.1 E-commerce and E-grocery ................................................................. 17

4.2.1.2 Internet usage for social activities ........................................................ 18

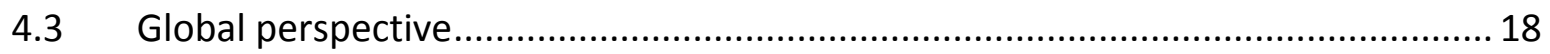

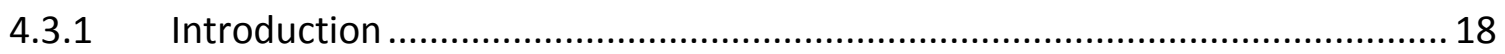

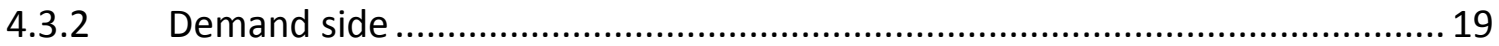

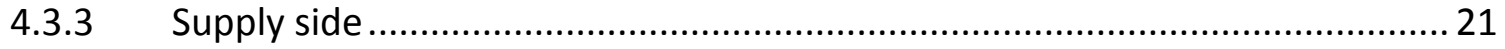

4.3.3.1 The primary care sector ........................................................................ 22

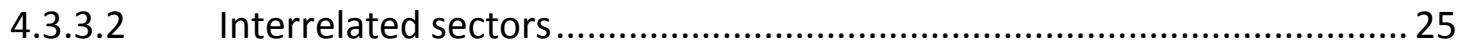

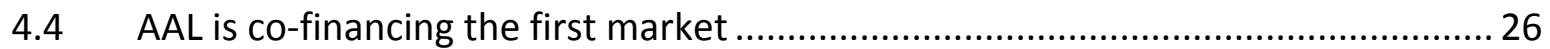

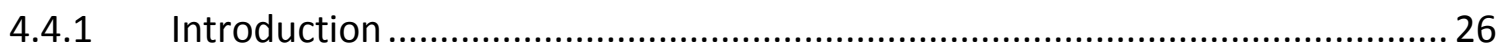

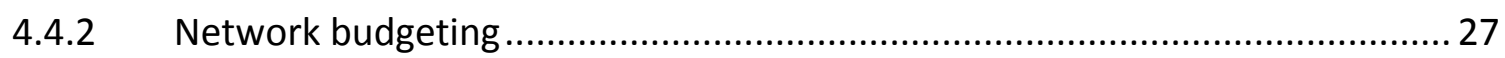

4.4.3 Is AAL co-financing the first market?.............................................................. 29

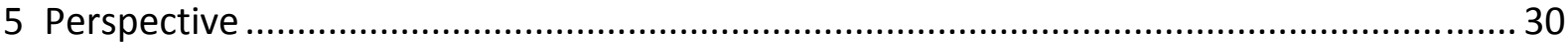

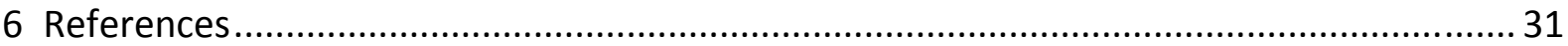




\section{Introduction}

When talking about "assisting systems", everybody has had experience of them using a car. The number of help, comfort and safety assistants is amazing. The possibilities include opening the doors and switching on the lights from a distance, giving warnings about unlocked safety belts and locked hand brakes, starting the windshield wipers when the first drops of rain are falling, taking over the braking procedure when the ground is slippery, opening the airbags when a crash is happening - and, if it is a more expensive car, even calling for emergency help automatically, sending the GPS data locating the accident. Automatic parking procedures are about to go into production. Even a middle-class car is provided with at least 70 processors and $3 \mathrm{~km}$ of cable, weighing approx. $65-70 \mathrm{~kg}$ altogether. The results of all these types of assistance can be seen: the number of accidents, of insured people involved in accidents, and of people killed in accidents is decreasing, at least in Germany. Here accidents in households now claim more lives (6361 in 2007) than car accidents (5011 in 2007, 4467 in 2008). And $80 \%$ of the persons affected in households were over 65 years old. ${ }^{1}$

\section{The economic impact of assisting technologies on nursing and medical care}

Assisting technologies aim to provide more support in the meeting of one's daily needs and the preservation of one's autonomy and quality of life. Continual developments in medicine, medical equipment, nursing and medical care are assumed to lead to new types of care being created. A high degree of social and economic relevance has been attributed to assisting technologies, as well as information and communication systems, by scientists and politicians alike, particularly in connection with the development, promotion and organization of so-called senior-friendly environments and with ambient assisted living (AAL).

Here the focus is especially upon the aged of the future, their specific demands and resources, which these technologies should be able to serve while adhering to their individual requirements. These new technologies can also be extremely relevant to people surrounding the elderly. They can make a considerable difference to the way in which people are able to live together - for example by assisting the nursing care provided by close relatives - and they may represent new opportunities to the providers of outpatient and inpatient nursing and medical care.

Assuming that an acceptance of technology and a competence to operate it are in place, the utilization of assisting technologies, information and communication systems in private

\footnotetext{
${ }^{1}$ Stat. Bundesamt (2008)
} 
households then depends on a willingness to invest money in such systems and on the financial scope of private households. Once assistance systems are perceived as necessary in order to master daily routines and preserve individual autonomy, this will have a fundamental impact on the demand for goods and services, leading to income and substitution effects. The extent of these effects, which can also work against each other, is a priori uncertain, however. But not only consumer structures will change; it may also be assumed that the utilization of these goods will have an impact on the division of time in private households and will influence labour supply.

New possibilities will open up in the field of nursing and medical care not only for consumers, but also for providers. On the one hand, this will affect the organization of goods and services supplied, with the utilization of these new technologies meaning that products need to be better adapted to individual consumer needs. On the other hand, new product and organizational structures - for example integrated care - could prove necessary.

The introduction of assisting technologies, information and communication systems to private households entails not only microeconomic effects, but also the issue of whether and to what extent it will have a bearing on macroeconomic developments. Through assisting technologies the various service providers could network their products far more effectively, and a cooperation between the various service providers could have an overall synergy, resulting in higher performance and yet a more rational use of resources. The result would be more rational nursing and medical care. The impact such gains in efficiency would have is a priori uncertain due to the numerous macroeconomic interdependencies and the integration of social security systems. The revenue and expenditure of social security systems like statutory health and nursing insurance could be affected, for example, and as a result of altered individual labor supply, the job market could be affected - in turn affecting the social security systems. Financial promotion of assisting technologies in private households could thus have positive external effects.

\section{Better health and its contribution to productivity and economic growth}

Discussion about the health economy as a growth industry not only includes the linking of health-related investments to growth, but additionally focuses on the foreseeable demographic development. Many experts neglect the potentials for growth and higher revenues in the face of increasing expectations within a population keen to enjoy healthy aging. Yet healthy aging as a growth determinant is a topic in itself.

Changes in the disease distribution, for example, are partially linked to demographic developments. In particular, an increase in chronic diseases can be observed. Allergies, asthma 
and diabetes are becoming widespread, due in part to aging, but also to environmental changes $^{2}$. Thus the medical treatment and disease management of patients with chronic diseases will increasingly substitute the treatment of acute diseases. From a population health point of view, the challenge of the future will be the prevention and early diagnosis of chronic diseases.

Older people live not only with some functional limitations, but also with chronic diseases and often with several diseases at the same time (multimorbidity). Prevalence data according to certain diseases and their need for nursing care are available for the population above $75 .^{3}$

Considering the changes in the demographic development and morbidity structure of the population within highly developed countries, a gain in healthy and productive life years will be essential in order to maintain a high economic standard. Therefore, it will be necessary not only to improve the efficiency of healthcare delivery and financing instruments, but also to increase investments in health. As former EU-Commissioner David Byrne puts it, "Health Equals Wealth". This strong relationship led him to consider a health status indicator as a new, additional convergence criterion for the expanded European Union ${ }^{4}$.

An improved health status is an investment in human capital, and alongside (private and public) capital and technical progress human capital is one of the three factors which explain economic growth and the fiscal stability of an economy ${ }^{5}$. A healthier population is more productive, and a higher functional capacity in an aging population leads to economically productive life-years. Improvements in health and education of the population are thus key factors in promoting growth and create better quality of life for citizens.

On this basis new markets are opening up, not only in healthcare itself but also in other areas, such as wellness and fitness, nutrition etc., through innovative medical and healthcare technologies, new products and services. These developments, which are closely related to ambient assisted living, lead to increasing turnover, higher revenue and growing profits as a basis for financing other parts of the economy, including the first health sector. In addition, new therapy professions, new study fields and new university research areas are emerging.

Nolte et al. (2002)

Menning (2006).

4 Byrne, D., Health equals wealth, speech held on the European Health Forum, Bad Gastein, 2003, http://europa.eu.int/rapid/start/cgi/guesten.ksh?p action.getfile=gf\&doc=SPEECH/03/443/=/AGED\&Ig=E

$\mathrm{N}=$ type=PDF, download November, 152003

5 See in detail Zimmermann/Henke (2005), p409-467 
As can be seen from a study sponsored by the Robert Bosch Foundation in 2007, reference human capital as a blending of health and education forms one of Germany's most important strategic resources ${ }^{6}$. Its quantity and quality decide how the future will be mastered. As human capital is one of the most important determinants of economic growth, the accumulation of human capital through investments in health and education is crucial for the innovative capacities of a national economy. Both sectors promote the growth of the remaining sectors of the economy, and through their own development they themselves become an essential source of growth.

Within the union of health and education, health is a prerequisite in the service of education. People can only use their human capital effectively if they are healthy and alive. In its "Global Development Report 2007", the world bank defined investments in human capital via health and education as the crucial prerequisite for success in today's competitive globalized world, whether as an individual or as an entire economic unit. For most people, employability is the only asset which needs to be made permanently more productive in order to sustain and continually regenerate prosperity. This means learning to make the correct decisions in order to stay healthy, and then adhering to them throughout life, even after retirement. With regard to the demographic shift, healthy life expectancy is gaining in importance even more.

The slogan "health equals wealth" is not restricted to the workforce, but refers to the whole population, especially to the elderly. From an economic point of view, depending on outside help ties up resources which to some part could be better allocated within the economic process. For example, nursing one's own parents can be very time-consuming, leading to withdrawal from the labour market, especially for women. Hence, the independent living of older people for as long as possible will free up time - and therefore affect the decision whether or not to work. On top of this, with a higher education level the opportunity costs of caring for an older person will be higher ${ }^{7}$.

But how can prolonged independent living for older people be achieved?

Great hopes rest on the usage of assisting technologies and the installation of AAL systems in private homes, which will be discussed in more detail in the following chapter. What follows is a discussion about the relevance of technologies to help people, especially the elderly, to maintain their independence regarding daily routines and with respect to outpatient and inpatient nursing and medical care.

Martin/Henke (2008).

7 As a side note, this is also relevant with respect to gender mainstreaming and equal conditions. 


\section{$4 \quad$ Status quo of AAL and possible growth markets with AAL}

Promoting the independence of older people forms a key part of the government's health and social care agenda worldwide, and new care delivery models supported by information and communication technologies (ICTs) are being developed to assist in realizing this goal. However, it can be stated that the research to date has not transformed AAL into a thriving economic development, though there is a great deal of potential. Within the bounds of these possibilities, two fields are to be mentioned: a) growth by itself and, above all, b) development in connection with health and (nursing) care.

To analyze the impact of AAL, the different aspects of the usage of assisting technologies has to be taken into account. First of all, the end user comes to mind - often characterized as an older person. However, AAL technologies are not only for older people. This view is too narrow as assisting technologies can make everyone's lives easier, e.g. electric roller shutters, automatic light and door control systems or daily safety support. In principle such technologies are meant for global markets - Europe, USA, Japan, etc. Whether or not such products are actually sold, depends not only on the mental and physical (health) status of the consumers, but also on their budget and preferences - many assisting technology are already available, but still too expensive.

However, there is no denying that AAL is of special relevance to people who are in need of nursing and medical care. Assisting technologies offer many flexible services focused on the needs and priorities of service users and carers. AAL systems facilitate improved communication and cooperation between professionals, users and carers, and between agencies. AAL will generate the development of wider adult service strategies for self-directed support and modernization of care management services. Overall, new possibilities will open up in the field of nursing and medical care not only for consumers, but also for providers. Growth paths exist not only via new products, but also through better organization: networking, optimization of processes etc. Therefore, new forms of remote health and social care delivery are seen as fields where AAL may develop into a competitive market. However, social care and health services must make more use of technology to provide more flexible services for an aging population at a local, regional and global level.

For some time now there have been research programs at the regional ${ }^{8}$, national ${ }^{9}$ and international level ${ }^{10}$, not only to foster research but also to promote the connection between

8 For Germany this means Berlin or Lower Saxony.

9 For a list of EU countries, see e. g. Commission of the European Communities (2006), p. 73.

10 For example, the Article 169 initiative on Ambient Assisted Living; for more information see Commission of the European Communities (2007) and www.aal169.org. 
research units and industry partners, enhancing partnerships between research institutions and firms for better public-private partnerships, ranging from pure theoretical research to the development and implementation of business models. Nevertheless, despite the academic and political discussion and numerous research programs at a national and international level, as well as financial support and subsidization, AAL can be characterized as an infant or emerging industry ${ }^{11}$. However, existing initiatives and research programs in the area of independent living are very fragmented. Some research initiatives exist at a regional, national and international level, but are not based on a comprehensive research agenda with a critical mass. In the following, such aspects are discussed in more detail, differentiating between the local, regional and global perspectives.

\subsection{Local perspective}

As AAL will enhance the possibility of independent living for elderly people, this will have numerous effects at a local level. Besides the direct effects for older people as end users, from a local perspective assisting technologies are especially useful for outpatient and inpatient nursing and medical care.

One starting point for looking at the consequences of AAL from a local perspective is the older person and his/her preferences. Some evidence exists that elderly people are trying to stay in their own homes for as long as possible. They want to remain in a familiar environment where they can even live with impairments to their vision, hearing, mobility or dexterity as they know all the "stumbling blocks". The same amount of independent living would not be possible if they had to adapt to and live in new domestic surroundings. Therefore, care concepts that include moving house have to be questioned. For example, multigeneration housing is not a catch-all solution, and neither are retirement homes or appartment-sharing communities. The so-called smart homes are seen as important when it comes to the implementation of AAL solutions. For more than 20 years, research and trial projects have built houses and apartments that are equipped with modern technology.

Contrary to the abovementioned "solutions", it seems as if such concepts are not ideal as they assume that older people should leave their familiar environment. Most older people do not, and are unlikely ever to live in new houses. Therefore, it is necessary to create home environments from the existing housing stock that are able to facilitate independent living. Independent living solutions often address daily support for safety ${ }^{12}$, reminders ${ }^{13}$ and user-

11 Commission of the European Communities (2007), p. 10.

12 Making sure entrance doors and windows are locked/closed when leaving the house or sleeping; checking for water or gas leaks; and turning all but one light off when going to bed, etc 
friendly interfaces ${ }^{14}$. Consequently this involves remedying poor housing features, providing assistive technology and establishing a safe and secure home environment. In this respect, housing is being asked to perform an increasingly important role in the provision of health and social care for older people, and an appropriately designed, high-quality home environment is fundamental to the provision of community care services, such as tele-care. Conversely, poor housing presents an important potential limitation to the vision of technologyassisted home care.

However, a well-timed upgrade of a home environment regarding adaptation to special needs can spread out costs over a longer time period. Therefore, financing of the implementation of AAL systems would be easier for homeowners to undertake.

The fact is that as people grow older they will increasingly rely on technology to be able to stay in their homes. For most people this is a - sometimes imperceptible - process and not a sudden event caused by an accident. Furthermore, people do not need extensive equipment with assisting technologies, but a particular system for their specific needs. Therefore, it is important to strive for a smooth adaptation. Older and elderly persons who face greater physical and mental challenges in maintaining their own health gradually need more extensive access to care and supervision at home. In this context areas such as tele-monitoring and telecare are of importance; and so are the newly-emerging personalized nursing and medical care services. It is well known that provision and support of rehabilitation or care at home to people suffering from e.g. chronic diseases can avoid hospitalization.

Overall, AAL may help to extend the time people can live in a decent way in their preferred environment by increasing their autonomy, self-confidence and mobility. However, taking note of the various individual preferences there is no single solution, but instead a broad spectrum of solutions. This partly implies a rethinking of policies and business models in order to overcome the current situation of fragmentation.

The abovementioned challenges can only be handled at the local level because of heterogeneity. An urban region, for example, may need other solutions than a rural area. Looking at the development to date, progress is more or less disappointing. Many initiatives exist at a local and regional level which is very fragmented, and none of those initial markets has reached a "critical" mass. The state of AAL markets could be characterized as mainly based

Memory problems tend to be associated with aging and thus support may be needed in taking medication or fulfilling household tasks.

14 For all sorts of equipment in the home and outside, taking into account the fact that many elderly people have impaired vision, hearing, mobility or dexterity. 
on local, custom-made solutions, no established structures, or networks; and with high risks and transaction costs ${ }^{15}$.

\subsection{Regional perspective}

AAL particularly addresses the issues facing an aging population and targets the needs of individual persons and their caretakers. Therefore, AAL is perceived as a potential growth market at a regional level. From a regional perspective there are at least two aspects which have to be considered.

Firstly, concepts of integrated care are taking shape at a regional level because a local area would be too small to generate a critical mass regarding the demand for AAL products - e.g. with regard to hospitals, specialized clinics, inpatient long-term care centres, security agencies, or sport and wellness centres, to name but a few. This is just an overview of the institutions which are involved in integrated care. The following highly simplified illustration concentrates on care of the elderly in order to reduce the complexity of suppliers which could be involved in integrated care and of the multiple connections between the local and regional levels.

Figure 1 is centred around the individual - the elderly person - deliberately neglecting the interdependencies with the social environment of older people, e.g. household structure, neighbourhood etc. At a local level institutions are located where everyday contact must be possible and where it can be assumed that a critical mass of demand for such services exists. At a regional level, institutions are to be found which are not capable of producing enough demand at a local level. Though it is a rather simplified illustration, the complex structure is obvious. To establish integrated care, a timely exchange of information is at least necessary between the different institutions at the local and regional levels. For this, assisting technologies or AAL technologies are indispensable, e.g. permitting more efficient and effective organization.

In local regions with a low population density, telemedicine is helping to bridge the distance to doctors and specialists by transmitting vital parameters and medical images (e.g. Scandinavia, Greenland). In most European countries, the transmission of radiology images is wellestablished to bridge the inadequate availability of radiologists during the night or at weekends, as well as to get a second opinion, etc. In Germany, telemedicine has been successful for some chronic diseases - patients with heart failure can be treated less expensively and 
with a better quality of life by equipping them with devices which transmit collected data to specialized telemedicine centres.

Figure 1: Integrated Care of the Elderly ...

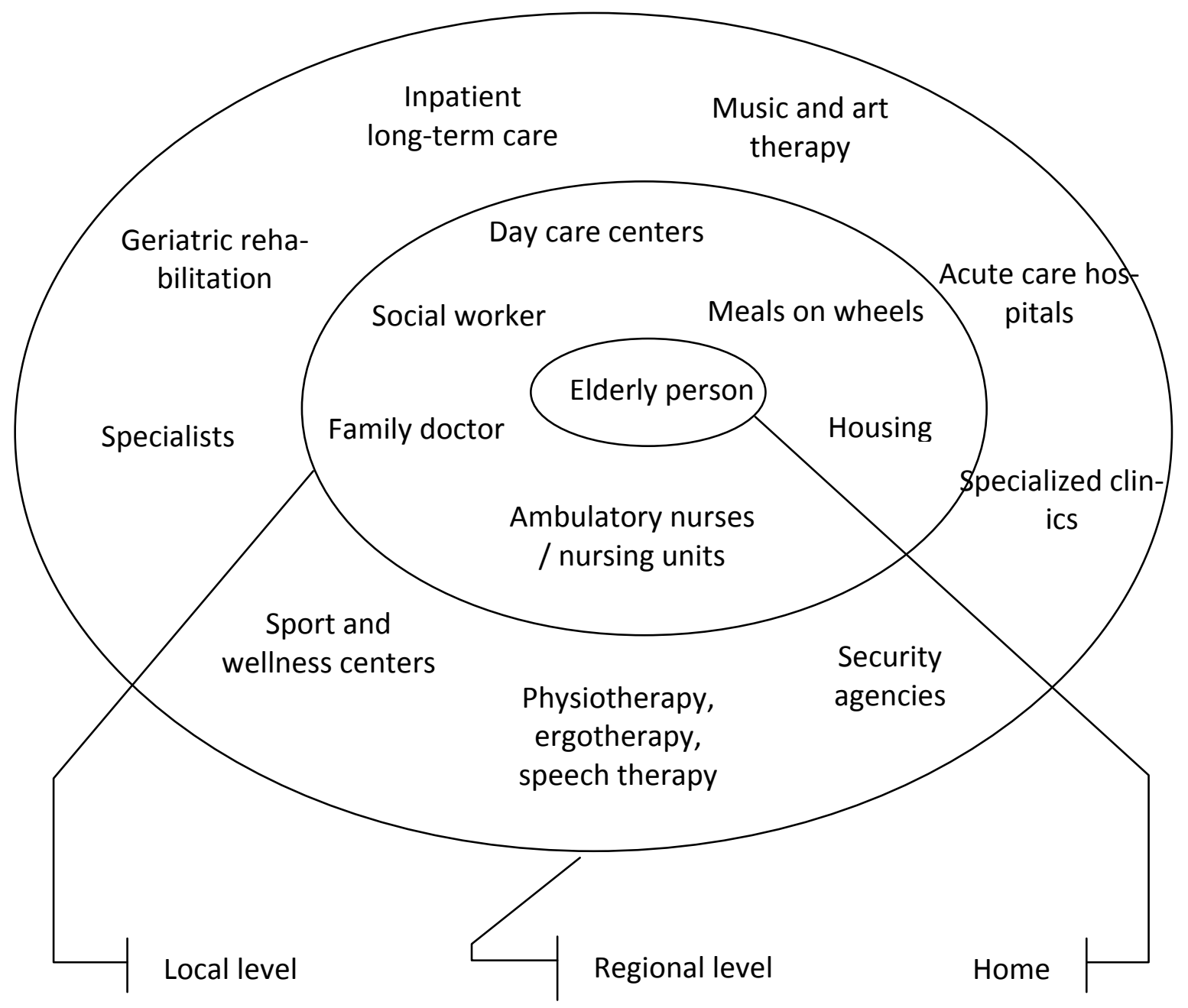

Source: Own

With the new emergence of rural areas with decreasing infrastructures, also in terms of medical services, telemedicine is one chance to support people living in these areas. Starting with a visual contact where the nurse or doctor is able to see a long-distance patient, and continuing with the measuring, collecting and transmitting of vital parameters such as blood pressure, weight, temperature, blood sugar and coagulation values, the remote expert is able to support a patient. For the fine tuning of coagulation inhibitors etc., a visit to the family practitioner is not really necessary - medication can easily be adjusted remotely if the correct vital parameters are known. In Germany there is a saying that people's homes are the "third location of health treatment" (besides inpatient hospital treatment and outpatient meetings with GPs and other physicians). Just recently, two big industrial players, GE and In- 
tel, announced a partnership to develop and market equipment for domestic care. Equally as successful as tele-medical diagnostics and treatment is tele-rehabilitation, either as the sole form of rehabilitation or as a follow-up to inpatient rehabilitation.

To give an example of regional structures in a rural area, the acute geriatric clinics and geriatric centres for Lower Saxony in Germany are shown in Figure 2.

Figure 2: Location of geriatric institutions in Lower Saxony

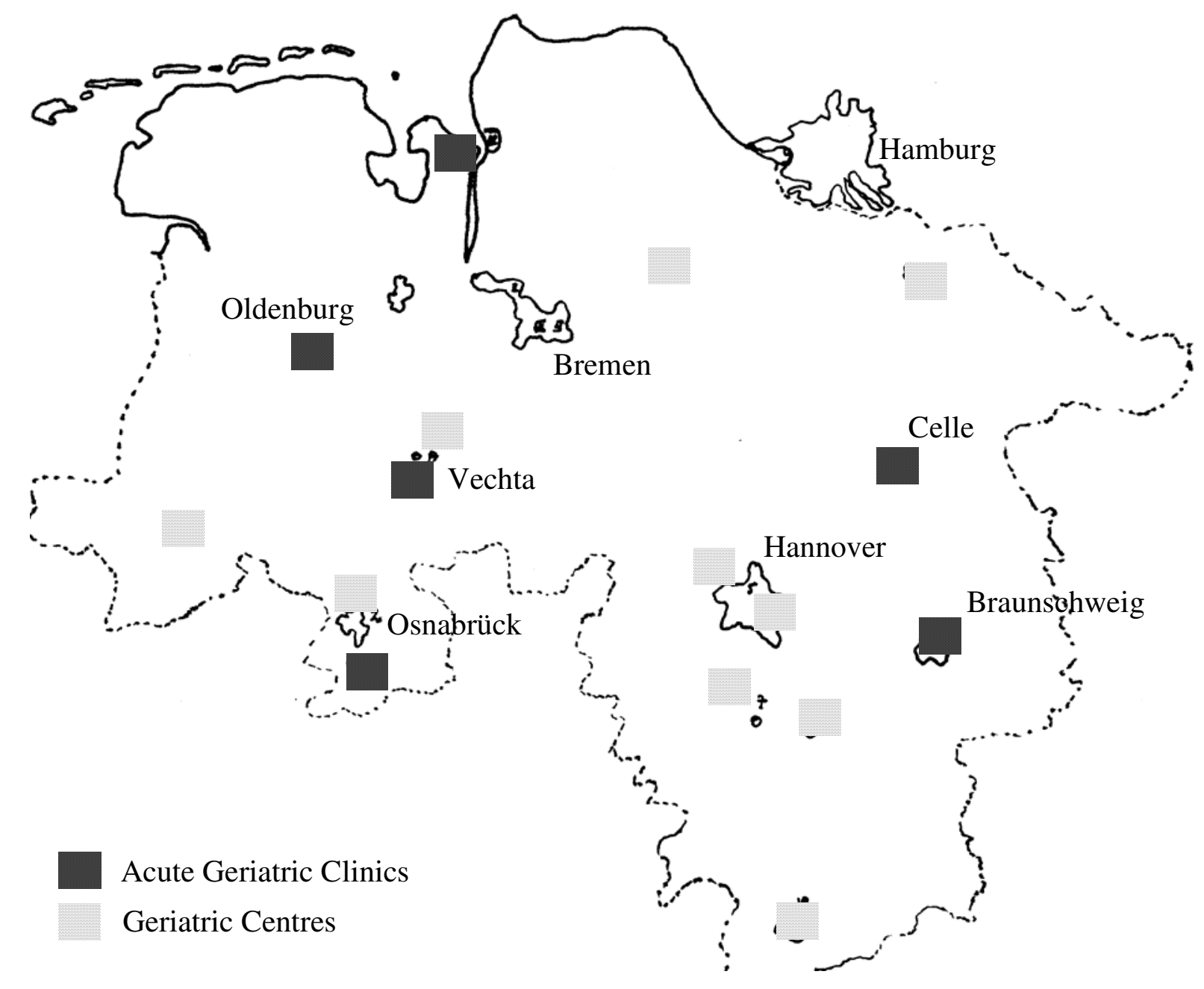

Braunschweig, Städt. Kliniken

Celle, St. Josef Stift

Friesoythe, St. Marien Stift

Georgsmarienhütte, Diakonie-Krhs.

Lohne, St. Franziskus-Hospital

Nordenham, Wesermarsch-Klinik
Bad Bevensen, Diana Klinik

Bad Salzdetfurth, Salze-Klinik

Coppenbrügge, Reha-Zentrum

Göttingen, Evang. Krankenhaus

Gyhum, Reha-Zentrum

Hannover, Henriettenstiftung

Hannover, Hagenhof

Lingen, St. Bonifatius Hospital

Osnabrück, Klinikum Osnabrück

Vechta, St. Marienhospital

Source: Landes-Arbeits-Gemeinschaft Klinisch-geriatrischer Einrichtungen in Niedersachsen (2008) 
The institutions are set up in so-called regional centres and it is easy to get to these centres because of the good regional connection by train or road. Bremen and Hamburg have their own acute geriatric clinics and geriatric centres - in Bremen there are four and in Hamburg eight institutions which are not shown in the figure.

The potential benefits of AAL systems and assisting technologies are recognized e.g. in health policy, but so far there are only a few examples of sustained, routine delivery of services. The numerous small-scale trials and pilot projects have generally failed to move towards more mainstream deployment. However, conflicting interests may hinder the development of integrated care as e.g. AAL systems may delay the demand for inpatient longterm care. On the other hand, assisting technologies may support the rehabilitation process so that rehabilitation can take place at home, controlled by the special centers at a regional level, increasing the demand for such institutions.

Secondly, the development of clusters in research and production will take place at a regional level as local units are per se too small to attract a reasonable number of firms and research institutes. There has to be a sufficient number of resources in science and research facilities, hospitals and pharmaceutical companies, medical technology, biotechnology, etc. to build a critical mass for an independent economic development ${ }^{16}$. It is thought that centers of excellence can be the focal point of such clusters as it can be assumed that industry is attracted by cutting-edge science, both as a source of ideas and cooperation and as the basis for its own $R \& D$ recruitment.

Science-industry collaboration is a necessity for developing a cluster, meaning that firms, universities and research centres must work closely together. Overall, knowledge relationships are needed for emerging sectors to thrive. Therefore, achieving a sufficient scale of activity implies a degree of regional specialization. Assisting technologies and AAL systems are suitable for the development of clusters because they are perceived as the core of new markets regarding goods and services. However, it is very likely that for clusters to succeed, effective multi-level governance arrangements will need to be in place, combining local, regional, national and even supra-national elements.

However, not only changes regarding the age structure are of relevance to further development. The economy and the job situation are pushing younger people and families to move to places where they can find education, work and schools for their children, etc. This mobility leads to a more rapid aging in the remaining population of rural regions. Hence, beside the services regarding outpatient and inpatient nursing and medical care, there are many 
other aspects which are closely related to daily routines where assisting technologies and AAL systems can be efficiently and effectively used. As these aspects are too manifold to discuss in detail, only some are briefly considered in the following.

\subsubsection{ICT technologies in combination with new services may help to overcome decreasing infrastructure}

Whereas villages and small towns in the 1980s were still typically equipped with a grocer's, a butcher's, a baker's, a post office, a family practitioner, a bus stop, etc., nowadays often none of the above exists. The volume of sales was not attractive enough to keep them alive. The resulting supply situation can be handled as long as the inhabitants are able to drive a car or can be supported by family, neighbours and friends.

Figure 3: Distribution of elderly population into urban, intermediate and rural regions, 2003

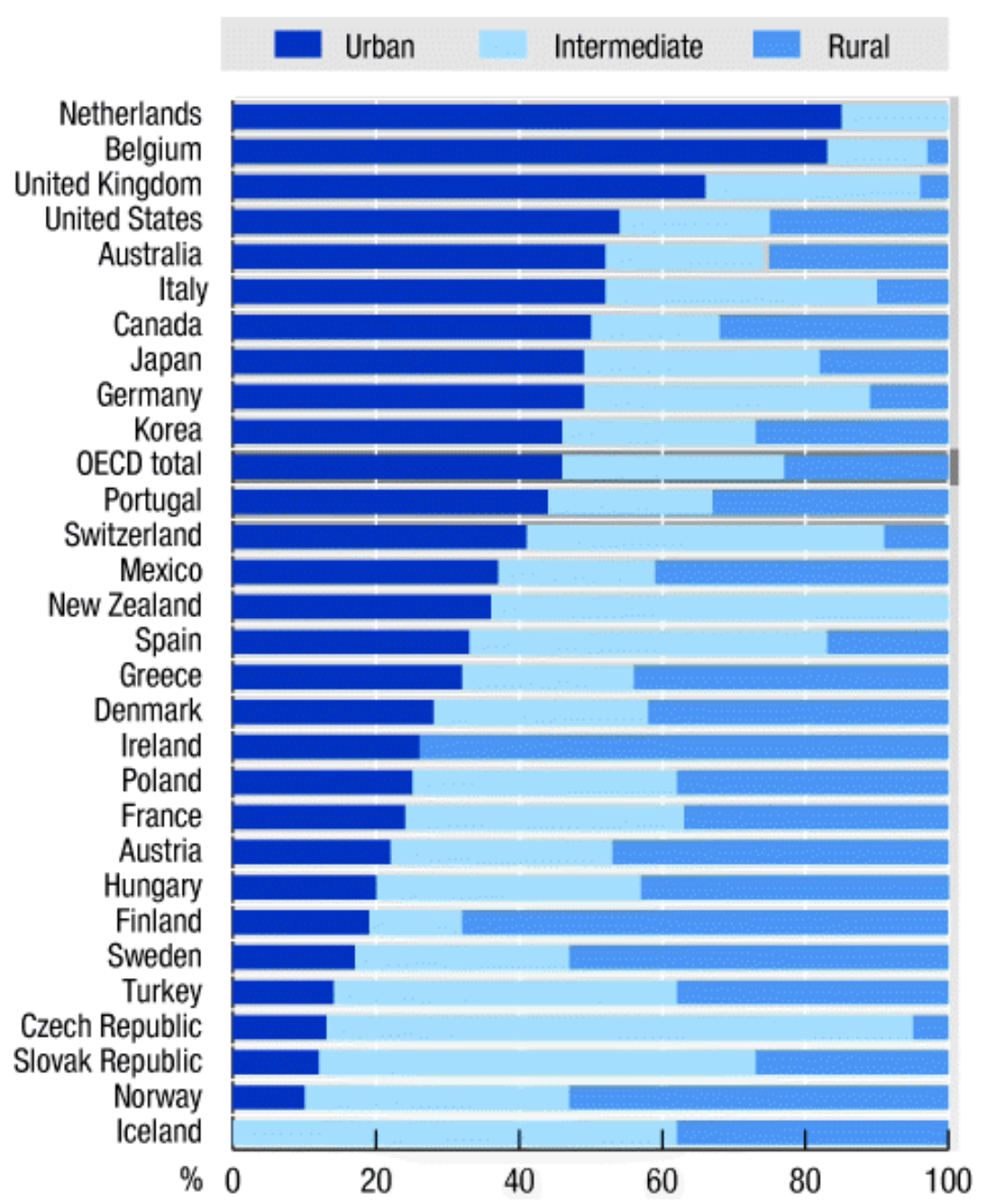

Source: OECD (2007): OECD Regions at a Glance; Distribution of elderly population into urban, intermediate and rural regions, 2003 
Across Europe entire regions can be discovered where younger people are hardly to be found and the supply and care situation for the elderly is therefore becoming difficult. Even in towns the basic supply is no longer always a given: shops concentrated in big malls outside or at the border of cities are of no use to immobile persons. E-commerce and E-grocery, telemedicine and extended usage of the internet are a chance to bridge that gulf.

Figure 4: $\quad$ Elderly dependency rate in urban, intermediate and rural regions, 2003

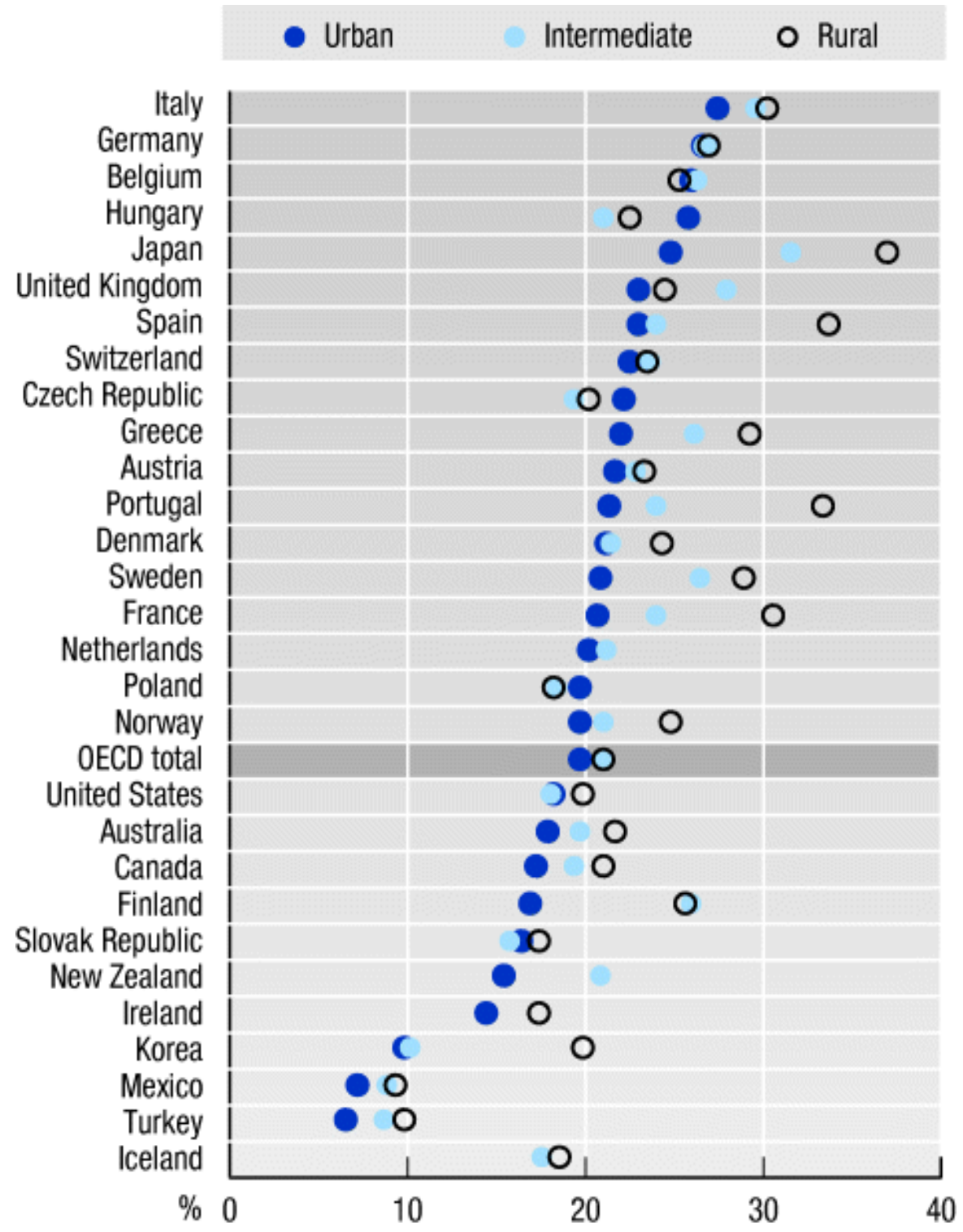

Source: OECD (2007): OECD Regions at a Glance; Distribution of elderly population into urban, intermediate and rural regions, 2003 


\subsubsection{E-commerce and E-grocery}

In many rural areas in Europe, and definitely in Germany and Switzerland, mobile grocery shops used to and still are supplying foods in rural regions without stationary groceries. But at least in Switzerland, the former METRO grocery bus has been replaced by the offer of "Le Shop", a successful and growing internet shop. In the UK this type of supply seems to be accepted, in Germany it is still at the very beginning. In the future, this type of e-commerce may increase, providing residents with everyday (household) essentials or convenience goods.

Figure 5: Theoretical Unexploited e-Grocery Potential in Europe vs. UK market in 2005

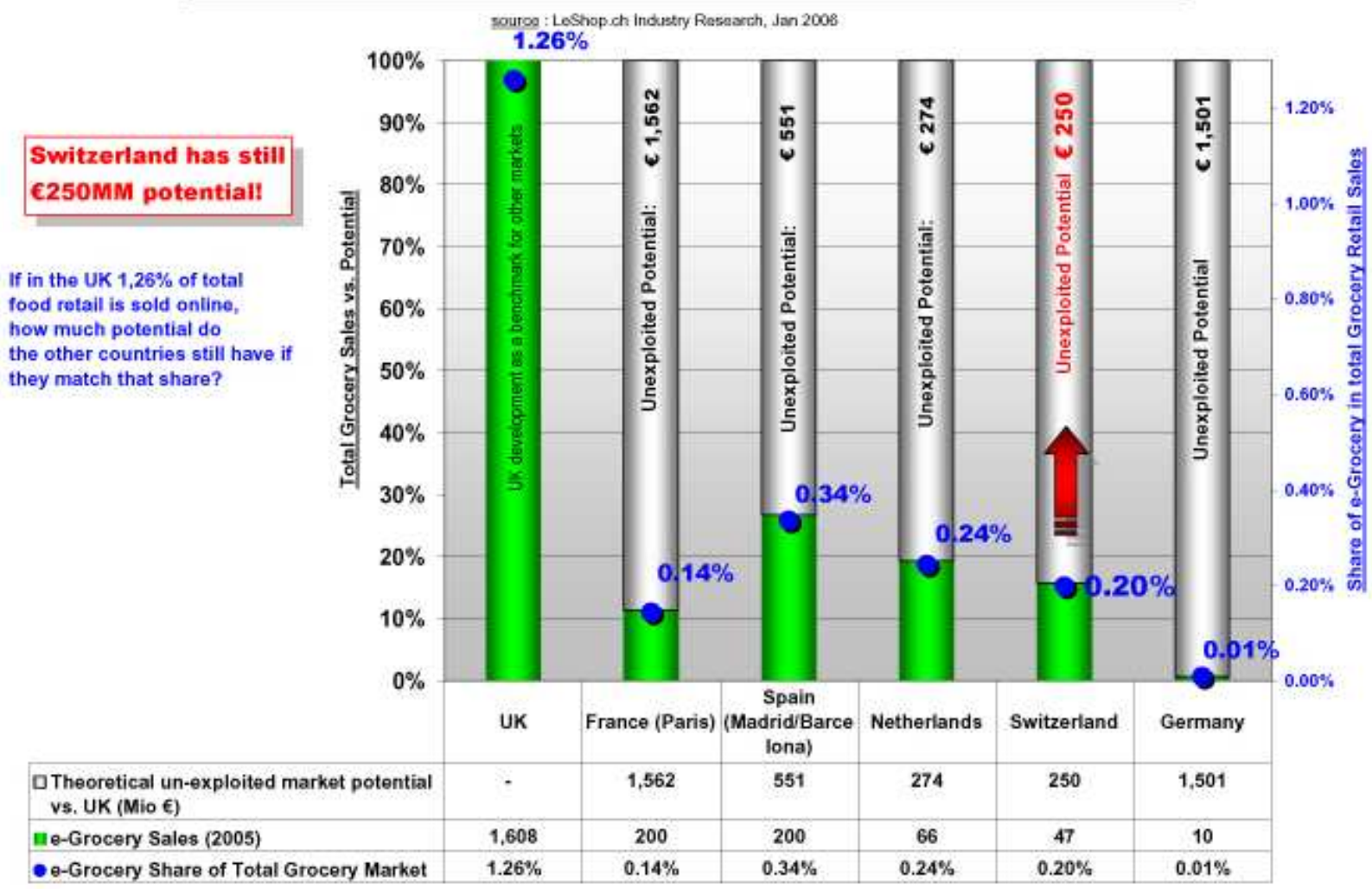

Source: Le Shop Industry Research (2005).

The older generation is not using the internet as much as younger people. But when they are using it, they know to provide themselves with the goods they need, as Figure 6 shows. 
Figure 6: Ordering of medication from internet pharmacies
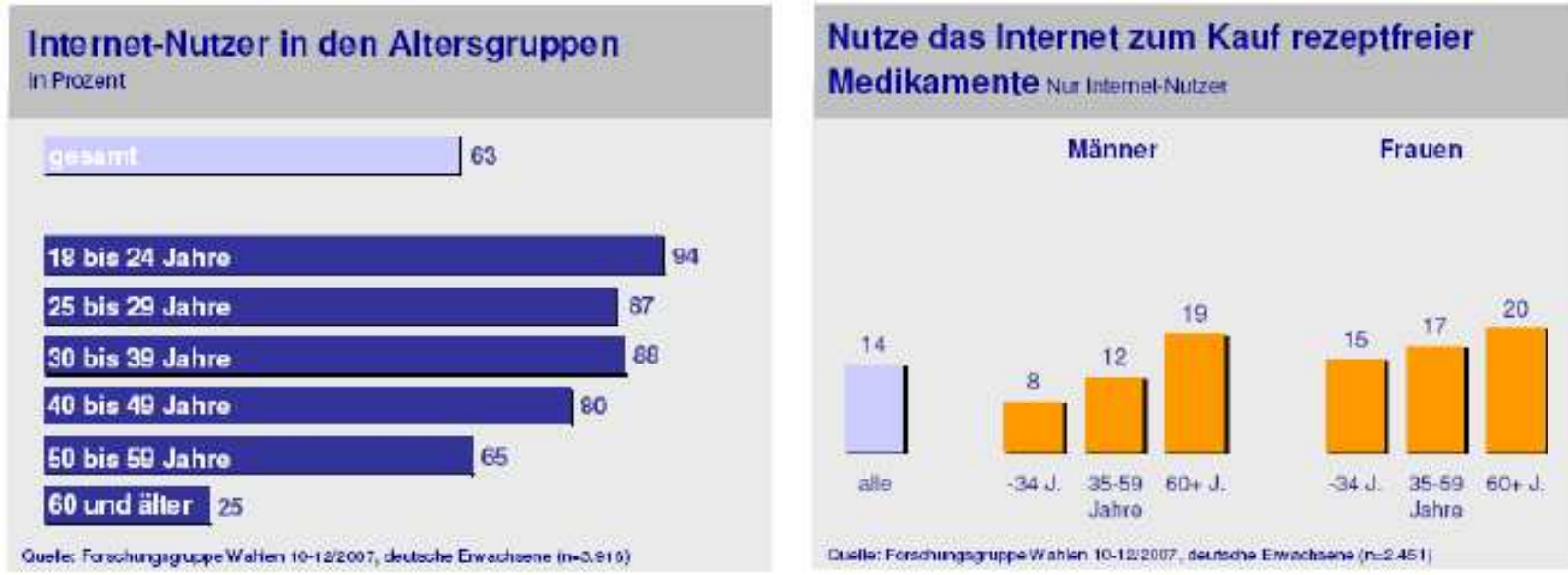

Source: Forschungsgruppe Wahlen Online GmbH (2007).

\subsubsection{Internet usage for social activities}

Internet chats using voice or video, providing a chance to share holiday pictures or play games together, are a new version of families or friends not living together being able to share live experiences. In order to be able to communicate with distant children and grandchildren, for a growing number of elderly people not only the internet, but also software such as Skype are something they have learned to use and to value. Nowadays communication channels are available for people who have lost the ability of mobility that are not intended to replace personal contacts, but can help to increase the number and quality of contacts.

\subsection{Global perspective}

\subsubsection{Introduction}

An increasing use of assisting technologies, especially AAL systems, entails not only local and regional effects, but from a global perspective also the issue of whether and to what extent it will have a bearing on general economic growth.

As often mentioned, new assisting technologies can play a vital role in supporting the ways in which millions of older or disabled people can maintain or regain their independence. It also has the potential to modernize the way in which many aspects of health and social care are currently delivered to the benefit of users, carers and service providers, as well as contribution and taxpayers. 
Generally speaking, the demand for healthcare and other service-intensive consumer categories has grown over time. "Healthy Aging" is seen as a major field for further economic development from a global perspective ${ }^{17}$. Hence the health and long-term care sectors are of special interest and may play a leading role because of the special character of these goods and services.

The production function for outpatient and inpatient nursing and medical care involves interdependent efforts by suppliers and consumers. Thus, the demand-driven effects are accompanied by supplier-induced demand which may push through an overall increase in the deployment of assisting technologies and AAL systems.

The discussed market potential may be even larger. It has to be pointed out that the focus on primary users - older people, (informal) carers and professionals involved in delivering support services - has restricted awareness of the economic potential of AAL technologies. In fact, numerous direct and indirect effects radiating from the core of healthcare to wellness or even travel exist.

However, many products are already on the market, and yet usage is rather minimal. The problem seems to be dissemination within the sector. It is supposed that incomplete information on both the demand and supply sides is the reason for the low development.

\subsubsection{Demand side}

With people living longer, they are liable to impairments of e.g. mobility, vision and hearing, and to become more prone to suffering from debilitating conditions such as cancer, heart disease, diabetes, dementia and other degenerative illnesses related to aging. Therefore, as people age, typically more input is required:

a) of assisting technologies to mitigate deterioration, and

b) of medical care to maintain health.

Furthermore, needs change over time and user groups are dynamic. The consuming habits, technical acceptance and technical capabilities of older people will be very different in the future from what they are at present ${ }^{18}$. In connection with the eagerness of older people to

17 Rijkers-Defrasne et al. (2008).

18 However, a recent study concluded that the lack of customers who are willing and able to pay for upgraded, improved or novel services is a major barrier in service (Howells et al. (2004)). 
live at home for as long as possible, this leads one to conclude high economic potential and growing markets with AAL.

The development of assisting technologies and AAL systems will have an impact on the costs of the service. Along with the volume of people involved, the trend towards increased life expectancy implies that the elderly will place more demands on the health system over an increasing period. Additionally, a greater incidence of illnesses related to aging and involving more expensive treatment or specialized care is likely to emerge, causing costs to rise. It is thought that the overall costs of the primary health care sector could be reduced by using technologies in connection with AAL systems.

However, it remains to be seen whether there will be enough spending power to cope with the demand. Given the information about the income and wealth of the current 45-60 cohorts, in many analyses a significant spending power is prospected for the future ${ }^{19}$. But these results should be viewed with caution as in most of the studies the economic consequences of restructuring the social security systems are not taken into account. The adopted measures are meant to reduce the financial burden of social security systems and to guarantee sustainability of the systems by reducing the overall level of social security benefits, especially of old age pension systems ${ }^{20}$. Therefore, it remains open whether there will be more spending power in the future, generating additional demand.

Moreover, income and substitution effects have to be taken into account. They will not be identical for all goods and services as AAL systems cover a whole range of goods from necessities to luxuries. Of special interest may be the integration of health and social care, or integration of home technologies with tele-services. It can be assumed that especially goods and services regarding health and care with low price elasticities may open up the market. So, for example, a 24-hour society envisions an increasing social demand for extended opening hours of services. Changes in the health sector will take place, encouraging the delivery of nursing and medical services via internet facilities. For example, the UK has witnessed a number of public sector initiatives towards 'telemediated' service delivery (online services such as NHS Direct) ${ }^{21}$.

Overall, the growth in consumption expenditure related to nursing, medical care and health is expected to accelerate in the future, reflecting the aging of the population, a diminishing share of health and nursing care expenditure covered by society, and new attractive nursing and healthcare products and services.

\footnotetext{
19 See e.g. Commission of the European Communities (2007), p. 9.

20 See e.g. Ginn et al. (2008).

21 http://www.nhsdirect.nhs.uk/. 


\subsubsection{Supply side}

It is well known that economic growth can occur in two different ways:

1. increased use of land, labor, capital and entrepreneurial resources by using better technology or management techniques and

2. increased productivity of existing resource use through rising labor and capital productivity

Both will be the case in the healthcare sector as assisting technologies will lead to better use of labor and capital and to increasing labor and capital production. Therefore, it is expected that the driving force behind the macroeconomic development caused by assisting technologies could be the healthcare sector in connection with nursing care, reflecting the increase in people potentially in need of health and care services.

The healthcare sector is one of the biggest macroeconomic branches in Europe. The health economy is seen as one of the "hidden champions" of the last 20 years, and further growth can be expected.

The primary factors driving productivity gains are:

- increases in the number of patients being treated,

- improvements in the quality of care patients receive and

- a slowdown in staff recruitment and the use of agency staff.

However, the impact of technological change may become visible only with a delay, and the benefits of AAL systems may appear foremost in quality changes. What makes technical change important in terms of economic growth are new technologies which are adopted widely in the economy. But the development up to now is falling well short of the aspirations $^{22}$. This applies both to incremental innovations that induce improvements in products or processes and to radical new technologies that can lead to the development of entirely new products, enterprises and even industries ${ }^{23}$. The process of diffusion is a gradual one.

22 Health services have massive purchasing power, yet can be late and slow adopters of new technology; see e.g. Wanless (2002).

23 The slow adaptation has negative consequences for both health and expenditure. Organizational and operational changes are needed. A recent foresight report noted the opportunities European collaboration brings for standardization, shared assessment of technologies and hence market creation; Braun (2005). 
The associated increase in potential output growth and labor productivity induced by this process is thus similarly gradual.

What can be said is that AAL as an industry is in its nascent status, but with much potential for economic upturn. Nonetheless, successful exploitation of new technologies often requires changes in work practices and the acquisition of new skills.

\subsubsection{The primary care sector}

To come to conclusions about economic development set off by usage of assisting technologies and AAL systems, the nature of the services provided and the competitive basis of the businesses has to be taken into account. The elderly care 'sector' is heterogeneous and characterized by a large proportion of non-commercial "businesses", a high proportion of nonprofit organizations and suppliers ranging widely in size. There are small firms with fewer than 20 employees and organizations with 250 or more employees.

Regarding the primary health care sector, a distinction has to be made between acute and preventive medicine, as well as rehabilitation therapy. In all three fields the use of assisting technologies can have a decisive influence. Experts expect that assisting technologies in combination with new medicine and medical technology will have synergetic effects.

With several millions of potential patients needing artificial devices and image-guided surgery techniques, the most important role for healthcare will be played by new technologies that produce non-invasive systems for diagnosis and care. Specific challenges include the cost of duplication in non-standardized medical files, the high administrative costs and coping with an aging population requiring prolonged medical care. Massive savings could be made by digitizing all diagnostic tests and images so that results are available to clinicians immediately. The cost of access to such records created and delivered manually is huge and causes unacceptable delays when processing patients.

Among the new sectors of the economy that can be expected to emerge over the next two decades is that of preventive medicine ${ }^{24}$. As the origins of various medical conditions are becoming understood at the molecular level, it is likely that ways will be found that will at least reduce the probability of individuals developing these conditions. A proportion of such individuals should be willing to invest time and resources for preventive treatments that can be provided either by public health care or the private sector.

24 Christidis et al. (2002) 
At the same time, the number of people requiring medical attention and rehabilitation therapy can be expected to grow, not only because of an aging population, but also because the number of people who survive serious illnesses but require continued medical support is going to grow. As a result, long-distance patient supervision using communications and analysis/sensor technologies is another major field where assisting technologies and AAL systems are applicable, and where through adequate usage a reduction in expenditure may be possible.

Early patient discharge from hospital due to the introduction of mobile health monitoring would save $€ 1.5$ billion in Germany on a yearly basis ${ }^{25}$. Even if this figure were questionable, it would still be clear that there are economic gains to be had from improving and optimizing the care processes. And yet, whilst there is now widespread experience of telecare through pilot and demonstration projects and the underlying technology is evolving rapidly to "bring more elements of the hospital into the home', its introduction into mainstream care practice has proved far more problematic.

However, elderly care consists of more than just medical care. Most of the elderly care businesses provide a mixture of customized services ${ }^{26}$ and standardized services ${ }^{27}$. Elderly care services cover a diverse range of activities, such as home care services for the elderly, day care and nursing and residential care home facilities. The usage of assisting technologies and AAL systems helps make such services more user-friendly and supportive to their customers. Therefore, competing for a share in elderly care activities appears to require that attention be paid to multiple aspects of the services provided. The emphasis on service quality is notable. The importance of paying attention to individual customer needs and the emphasis on customized as opposed to standardized services suggest that continuous forms of largely 'hidden innovation' are likely to be more significant than explicit innovation through the introduction of new services. Changes could take place in at least one of the following fields: the provided services, the means of producing services, the means of delivering services. New technologies may also be related to other forms of change, such as organizational or relational change. Assisting technologies and AAL systems may help in better customizing the services.

In connection with the adaptation of new technologies it can be assumed that the skills of the workforce will become more and more important. This perhaps points to a significant level of 'soft' innovation, which is not technological but procedural and/or organizational. Changes in the technologies utilized tend to be associated with other forms of change, but

\footnotetext{
25 http://europa.eu.int/information_society/events/ict_riga_2006/doc/presentations/ps6-saeteroey.pdf 26 Customized services are defined as services that are changed for each individual customer.

27 Standardized services are defined as services which do not change between individual customers.
} 
equally not all forms of change (such as organizational and relation change) depend on new technologies. This again highlights the importance of non-technological innovation. A high level of 'soft' innovation in care for the elderly (and similar) activities suggests itself.

Changes in the technologies require closely related changes in skills, and thus the training and retraining of staff. This suggests that new technologies are not easily absorbed into elderly care businesses, and that therefore these businesses should not be regarded as mere passive adopters of technologies. However, considerable training and retraining is generally required even in the absence of significant technological change, showing that technological innovation is only one dimension of the wider process of innovation, learning and adaptation in elderly care businesses.

It can be assumed that a higher level of productivity improvement can be achieved by using assisting technologies and AAL systems. Productivity in the primary care sector is difficult to measure but there are many reasons to believe that resources can be used more effectively. Current use of information and communication technology (ICT) is extremely poor, changes in the skill mix of staff can go further and there is significant scope for better management (and less bureaucracy). If more decisions were taken in a holistic way, recognizing the interrelationships between many of the resources in the system, the health service would be more effective. For example, better integration of health and social care for older people could reduce 'bed blocking' to low levels and free up expensive hospital beds for many more patients.

AAL may help to reduce the complexity of interrelationships between health and social services organizations, housing and service providers and the recipients of care. The development of assisting technologies and the employment of AAL systems may cause significant or complete change to the means of producing services, and to interrelations with other businesses, yet slightly less change to the means of delivering services, and to interrelations with customers or clients.

A fully functional AAL system requires that the various service providers network their products effectively. A cooperation between the various service providers could have an overall synergy, resulting in higher performance and yet a more rational use of resources.

So not only the household sector may induce additional demand; suppliers in the health sector and interrelated branches will also employ assisting technologies and AAL systems:

- to adapt to the assisting technologies and AAL systems at home

- to gain competitive advantages 
- to reduce or curb the increasing overall costs of the health sector.

\subsubsection{Interrelated sectors}

Positive effects of AAL on the economy as a whole are not confined to the healthcare sector. Overall, the elderly care 'business' is confronted with the task of using advanced technologies and introducing new services. With assisting technologies and AAL systems at hand, other sectors will use the technologies for themselves or adapt their goods and services because of productivity gains and cost reduction in providing services. Use of information and communication technologies facilitates the production of goods and the provision of services more efficiently and rapidly with the assistance of computerized systems. Therefore, technological change is not confined to the health sector. AAL systems may also be used by personal services, retail trade, amusement and recreation services and miscellaneous repair services, to name but a few.

Progress in the health sector is accompanied by two parallel developments which share the market and only appear to compete with each other.

3. "Lifestyle medicine" is driven by services. Visions exist of pharmacies becoming wellness shops, of clinics focussing on patient customizing, of foodstuffs and drinks displaying more and more health attributes, of tourism developing a new sub-branch in psychosocial health and even of wellness in the workplace, which will play a key role regarding the competence of firms and their competitive strength.

4. Elderly care 'businesses' will become more personalized and tailored to the individual as:

- diagnostics become more predictive;

- therapeutic interventions and nursing and health care services become more preventive;

- AAL systems become more supportive.

Beside the new technical developments in assisting technologies, gains in efficiency through better organization, networking etc. will occur, supporting even more economic growth. These technologies may enable organizational re-engineering to achieve significant labour productivity improvements, through, for example, workforce scheduling. One of the last things that a manager wants to see is unused capacity. Meeting the demand profile implied by the forecasts of e.g. incoming calls and contacts is a difficult combinatorial optimization problem. New software will be used by an increasing number of service centres so that up- 
swings and downswings in call frequency are matched by the appropriate number and type of customer agents.

The impact such gains in efficiency would have is a priori uncertain due to the numerous macroeconomic interdependencies and the integration of social security systems. The income and expenditure of social security systems like statutory health and nursing insurance could be affected, for example, and as a result of altered individual labor supply, the job market could be influenced - in turn affecting the social security systems. Financial promotion of assisting technologies and AAL systems in private households could thus have positive external effects.

Assisting technologies, AAL systems and the usage of new services may lead to an increase in the use of capital over time. Furthermore, the level of productivity improvement which can be achieved will rise and increase efficiencies across the health and social care system.

Perhaps Baumol's Cost Disease may have to be rewritten ${ }^{28}$.

Following this train of thought leads to the question of how the expenditure could be financed.

\subsection{AAL is co-financing the first market}

\subsubsection{Introduction}

The global or macro perspective refers again to the financing side of AAL and the figure already shown above ${ }^{29}$. What is needed from an economist's point of view is a sort of "gold standard" for the funding of healthcare, i.e. financing and purchasing structures in health services. To many experts, funding healthcare is a book with seven seals. This is why it could serve as a good example for an academic attempt to support the development and implementation of health targets by encouraging the efficient and appropriate use of scarce resources in health policy planning. Health target strategies, specifically in the areas of treatment options, outcomes research, AAL and drug interventions, should include answers in regard to financial gaps due to aging and the demographic challenges.

Fiscal sustainability has a lot to do with long-term financing of healthcare through general revenue (i.e. taxes), payroll taxes (i.e. contributions by employers and employees), risk-

\footnotetext{
28 For a similar conclusion see Triplett/Bosworth (2003).

${ }^{29}$ The Funding and Purchasing of Heath Care - A Book with Seven Seals, in Journal of Public Health, Vol. 14, p. 385-390 
oriented premiums, out-of-pocket-expenditures, co-payments etc. In terms of a gold standard, large financing pools are necessary to avoid risk selection or, in other words, no risk selection, but risk adjustment is asked for from a global perspective.

Given a population-wide coverage of health services, tax financing on the basis of the abilityto-pay-system is one approach and funding through social security on the basis of the benefit or insurance principle is the other way to finance health care. Within the second approach a risk-adjustment process is necessary and a prerequisite for fair competition.

In addition to the question of whether a Beveridge or a Bismarckian System should be preferred, much academic work has been done on intergenerational accounting (e.g. publications by the $\mathrm{OECD}$ ) and the measurement of conflicts between generations in face of the demographic challenges. But politically not much has happened so far. Partially funded systems based on the idea of saving money for old age would balance risk management in favor of the severe demographic challenges that are faced by many nations. New ways of funding health care are at present high on the agenda.

Apart from these overall options of financing, which are used quite differently across Europe and which describe different ways of collecting money ("external financing"), purchasing of health services from hospitals and rehabilitation institutions, from office-based physicians and purchasing of drugs, remedies, medical appliances and so forth is the second important aspect to be considered in the context of health care. It can be called "internal financing", i.e. the reimbursement or payment of each healthcare service in or outside of ambient assisted living (AAL). In terms of a gold standard, all services should be delivered according to medical guidelines, best practices and in regard to outcome measures. The reimbursement systems should be less revenue-oriented but more outcome-driven and not reimburse on a fee-for-service-basis. With regard to the health economy, the situation changes automatically when services are not reimbursed through the insurance funds or through public health systems like in the UK.

\subsubsection{Network budgeting}

In many countries the overall goal is to overcome segmentation in healthcare and to work on an integrated and quality assured medical care network. To achieve this target, a functional approach to healthcare is indispensable for necessary reforms. For an integrated care delivery system new forms of selective contracting between providers of health services and sickness funds are needed. The provision of medical treatment and of nursing care, including rehabilitation, systematically belong together, and should be covered through joint remuneration by way of network budgeting and new kinds of fee-per-case payments. Compre- 
hensive "all-round care" is the new subject of financing. In the figure shown below, healthcare for elderly patients is taken as an example of the desired integration of health service providers. So far, no golden rule for purchasing all these services can be seen, so that more competition is probably the answer to this problem.

Proposing such a network is much easier than accomplishing one. Pricing, purchasing (e.g. through DRGs, reference prices or on the basis of a fee schedule), expenditure and financing (taxes, contributions, premiums etc.) of health services represent a highly complex picture for all the participants. It raises more questions than answers, and hopefully socially bound competition may help to develop further the institutional details in providing, funding and purchasing the healthcare required, not only for the elderly but for the entire population.

Figure 7: Integration of health service providers in health care of the elderly

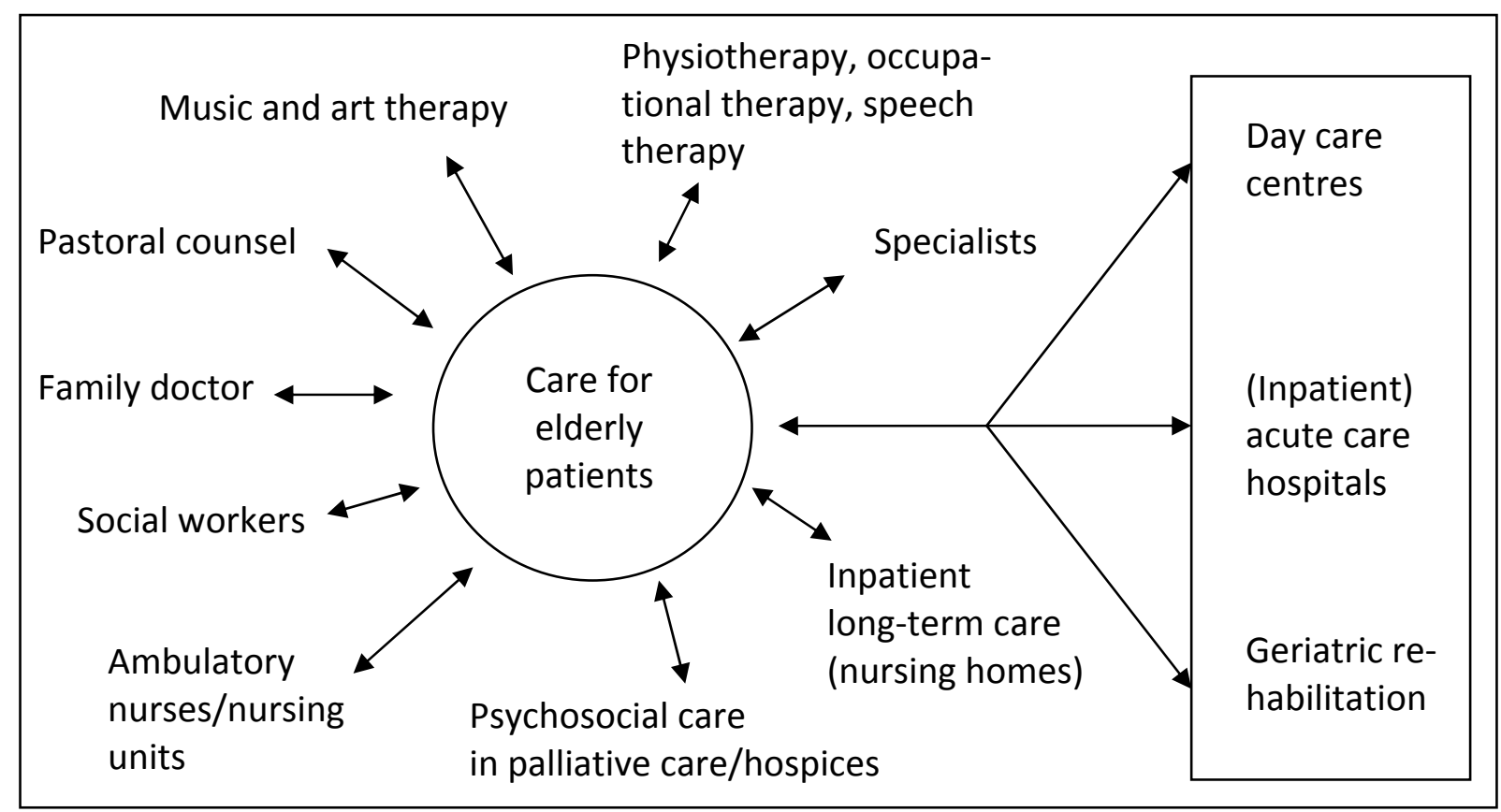

Source: own

However, if an integrated and quality assured medical care network can be established, it will lead to gains in efficiency and effectiveness. In this case, with the same amount of input more health output (in quantity) can be achieved or, with less input, the same amount of health output as shown in Figure 8: The starting point is A and through innovations and better use of assisting technologies and AAL systems a higher productivity level could be reached - the point $C$. Alternatively, it would be possible to maintain the level of health output as a constant, but then lower input would be needed - case B. 
Figure 8: Self-financing through technological progress and innovation

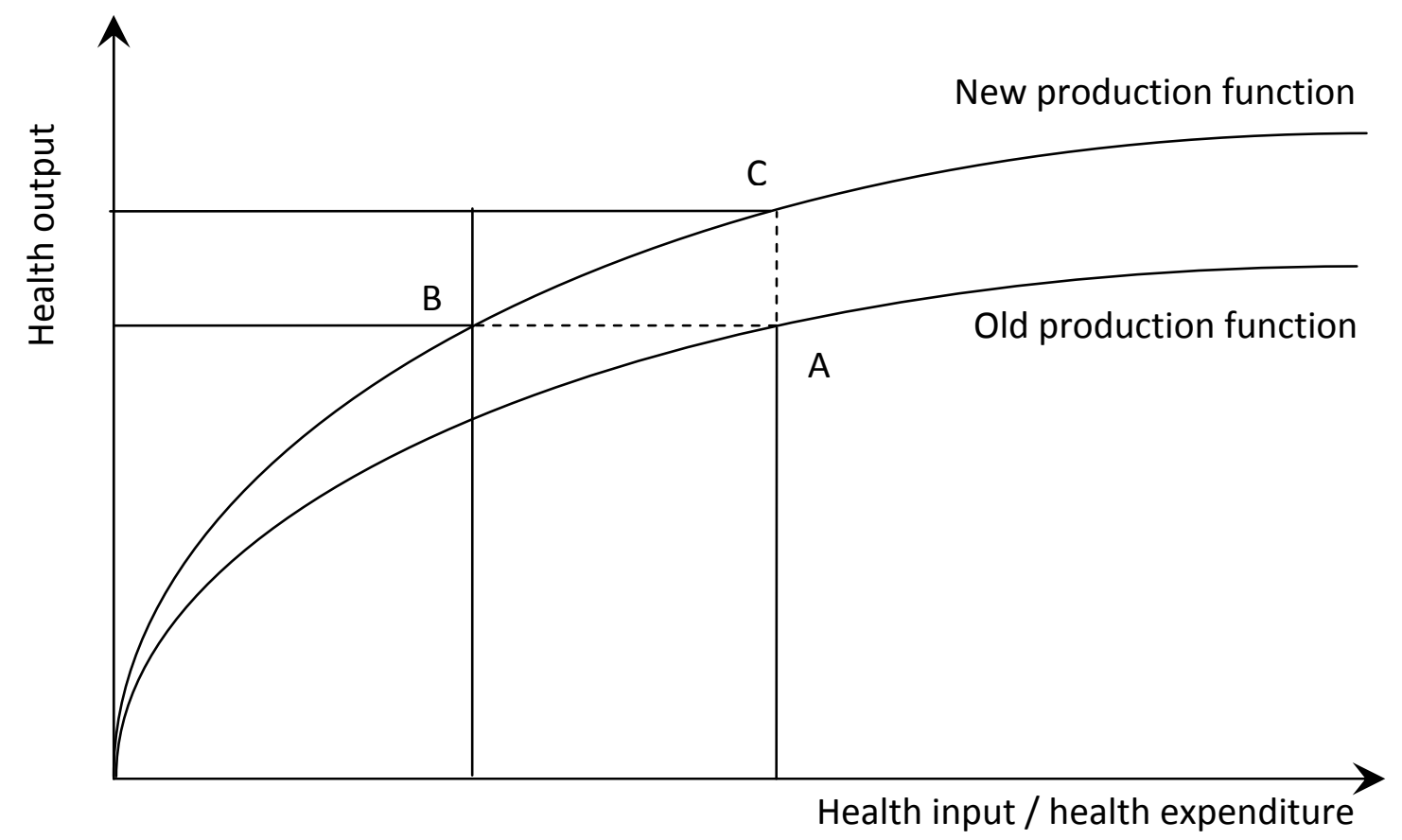

Source: Henke (2006): Health as a Macroeconomic Driver. The health market and its contribution to productivity and economic growth. 9th European Health Forum Gastein, p. 5.

In case $B$, on the one hand expenditure decreases and lower financial resources would be necessary. On the other hand, resources would be set free, which would be allocated to other economic sectors and lead to an overall higher productivity of the economy. Therefore, at least a part of the financial problem may be solved by the healthcare sector itself.

\subsubsection{Is AAL co-financing the first market?}

A working hypothesis is that the increasing "second health care market" is supporting and financing the "first health sector" in the overall health economy. The first sector refers to a protection with healthcare services for everyone in tax-financed or in social security types of systems, whilst the second healthcare market functions like the normal economy in industrial countries, i.e. through innovative products and services in growing markets, e.g. AAL. To justify this hypothesis there are several considerations which need to be taken into account and hopefully empirically tested in the future.

a) Improving the health of the population is an investment in human capital. And human capital (health and education), its quality and quantity, is one of the factors (besides capital investment and technical progress) that explain economic growth and fiscal stability. A healthier workforce is a more productive one and a higher functional capacity in 
an aging population leads to economically productive life-years. Prevention and health promotion are the key factors in this context. And better health, education and empowerment of the population are part of this endeavour.

b) On this basis, new markets open up not only in healthcare itself, but through innovative medical and healthcare technologies, new products and services in the wellness and fitness area, in nutrition, housing and other areas as well. These developments lead to an increasing turnover, higher revenue and growing profits as a basis for financing other parts of the economy, including the first health sector, the tax basis of which are wages and salaries.

c) A third factor results from the fact that private expenditure and private facilities, e.g. AAL systems, keep the people away from public services in the traditional sense. Nursing home care for the elderly is less expansive and other public systems save expenditure through a healthier population in an ambient assisted living environment. Thus prevention and rehabilitation, for example, are very important parts of the health economy.

d) In addition, new professions in therapy (e.g. occupational and speech therapists), new study fields (e.g. medical engineering) at the universities and research areas (e.g. palliative medicine) are developing at the same time.

With a shrinking population (and economy?) all over Europe, we need a healthy "grey population", with its positive effects on tax revenue, consumption and growth. In tourism, housing, shipbuilding, education, chemistry, etc. nobody is cutting back on employment, expenditure or profit in a market-oriented society. On the contrary: a booming and flourishing economy is a value in itself. Thus we should start by calling a halt to the traditional arguments: that growing expenditure in healthcare leads to a cost explosion, that a higher and higher percentage of healthcare expenditure to GNP or higher contribution rates is naturally bad, that labour costs are always too high. Nobody knows the optimal rate of healthcare expenditure to GNP in an economy. But it is a fact that health, healthcare and the health industry are parts of the health economy, with a value added of around $11 \%$ and 4.4 million employees in Germany.

\section{$5 \quad$ Perspective}

Returning to our introduction, the following questions now arise: "Why can't homes be as helpful, supportive and caring as cars?" Why do we still need keys to open the front door? Why doesn't the light switch on automatically when the door is opened? Why are we not warned about devices that are still switched on when we leave our homes by the front door? Why isn't my home able to tell that I am in need - and organize help? Why do we accept homes without intelligent fire detectors, knowing that more than 6000 people die in fires every year?

Imagine homes with smart meters for electricity, water and gas. On the one hand, smart meters can give an exact overview of the consumption of residents. They can visualize the con- 
sumption on a daily basis, from one week to another, from weekends to weekdays etc., thus increasing awareness. On the other hand, they can easily be used to determine that an elderly person used water, electricity etc. late at night but not again the next morning. Detecting irregularities and/or a failure to use gas, water and electricity supplies can help to reveal an emerging illness. Of course, nobody should know absolutely everything about a resident's daily routine - but the home itself could know and learn and self-configure. The home could in suspicious circumstances - send information. A sudden increase in wakeups during the night could, maybe, cause a traffic light signal to switch to amber; no life signs at all would switch it to red. Then somebody could start to care ${ }^{30}$.

\section{References}

Braun, Anette (2005): Healthcare: Key Technologies for Europe. A report from EC high level group on Key Technologies. Brussels: European Commission.

Christidis, Panayotis / Hernandez, Hector / Lievonen, Jorma (2002): Impact of Technological and Structural Change on Employment: Prospective Analysis 2020. Background Report. Study for the Committee on Employment and Social Affairs of the European Parliament. IPTS - ESTO. Report EUR 20258 EN. European Commission Joint Research Centre (DG JRC) - Institute for Prospective Technological Studies (ipts) - European Science and Technology Observatory (ESTO).

Commission of the European Communities (2006): Commission Staff Working Document. Accompanying document to the Communication from the Commission to the European Parliament, the Council, the European Economic and Social Committee and the Committee of the Regions. Ageing well in the Information Society. An i2010 Initiative Action Plan on Information and Communication Technologies and Ageing \{COM(2007)332\} final. SEC (2007) 811. 14 June 2007. Brussels: Commission of the European Communities.

Commission of the European Communities (2007): Communication from the Commission to the European Parliament, the Council, the European Economic and Social Committee and the Committee of the Regions. Ageing well in the Information Society. An i2010 Initiative. Action Plan on Information

\footnotetext{
${ }^{30}$ There have been few new developments made concerning this type of device during the last 20 years. At least for Germany, further development is not attractive for the medical devices industry: emergency call systems fall under Book V of the Social Law (SGB V) responsible for the health system, not Book IX of the Social Law (SGB IX) responsible for long-term care. The limitation of SGB $V$ is that either devices (including the services relating to them) are part of the catalogue of services paid - or they are not. So either everybody has to be offered a more sophisticated emergency call device or nobody. There is no chance of obtaining some money to fund the installation of a basic device, and then on private initiative individuals could add some money to purchase a better, more sophisticated one. So the few companies offering such a device in combination with their services import one from Finland (VIVAGO). It is able to detect whether it is being worn, whether the person wearing it is moving or lying down somewhere: activity profiles are collected. It can be used to press an emergency button - but it is also able to recognize an emergency situation by itself.
} 
and Communication Technologies and Ageing \{SEC(2007)811\}. COM (2007) 332 final. 14 June 2007. Brussels: Commission of the European Communities.

European Commission (2006): Creating an Innovative Europe. Report of the Independent Expert Group on R\&D and Innovation appointed following the Hampton Court Summit and chaired by Mr. Esko Aho. Luxembourg:

Forschungsgruppe Wahlen Online GmbH (2007): Internet-Strukturdaten. Repräsentative Umfrage IV. Quartal 2007.

Ginn, Jay / Fachinger, Uwe / Schmähl, Winfried (2008): Pension reform and the socioeconomic status of older people in Britain and Germany, in: Naegele, Gerd / Walker, Alan (Hrsg.): Social Policy in Ageing Societies: Britain and Germany Compared. Basingstoke: Palgrave Macmillan.

Howells, Jeremy / Tether, Bruce / Blind, Knut / Edler, Jacob / Hipp, Christiane / Montobbio, Fabio / Corrocher, Nicoletta / MacPherson, Alan / Banach, Donna / Gallouj, Faiz / Djellal, Faridah / Gallouj, Carnal (2004): Innovation in Services: Issues at Stake and Trends. Studies on Innovation Matters Related to the Implementation of the Community "Innovation and SMEs Programme". Final Report. Studies on Innovation Matters Related to the Implementation of the Community 'Innovation and SMEs Programme'. INNO-Studies 2001: Lot 3(ENTR-C/2001). Brussels - Luxembourg: ESRC Centre for Research on Innovation and Competition (CRIC) - Institute of Innovation Research, University of Manchester.

Le Shop Industry Research (2005): Industrie-Zahlen Europa. Le Shop Industry Research: http://info.leshop.ch/php/BusinessLeShop.php?LeShopMenuld=186\&lge=de, 12. Mai 2010.

Martin, Karl / Henke, Klaus-Dirk (2008): Gesundheitsökonomische Szenarien zur Prävention. BadenBaden: Nomos.

Menning, Sonja (2006): Gesundheitszustand und gesundheitsrelevantes Verhalten Älterer. GeroStat Report Altersdaten. 02/2006. Berlin: Deutsches Zentrum für Altersfragen.

Nolte, Ellen / Scholz, Rembrandt / Shkolnikov, Vladimir / McKee, Martin (2002): The contribution of medical care to changing life expectancy in Germany and Poland, in: Social Science \& Medicine 55, Heft, S. 1905-1921.

Rijkers-Defrasne, Sylvie / Amanatidou, Effie / Braun, Anette / Pechmann, Agnes (2008): Detecting and analysing emerging science and technology issues: the EFMN Issue Analysis, in: foresight 10, Heft 6, S. 90-102.

Triplett, Jack E. / Bosworth, Barry P. (2003): Productivity Measurement Issues in Services Industries: "Baumol's Disease" has been Cured, in: Economic Policy Review 9, Heft 3, S. 23-33.

Wanless, Derek (2002): Securing our Future Health: Taking a Long-term View. Final Report. London: HM Treasury.

Zimmermann, Horst / Henke, Klaus-Dirk (2005): Finanzwissenschaft. Eine Einführung in die Lehre von der öffentlichen Finanzwirtschaft. München: Vahlen. 